\title{
Publisher Correction: Supporting the Message, Not the Messenger: The Correlates of Attitudes towards Black Lives Matter
}

\author{
Omeed S. Ilchi ${ }^{1} \cdot$ James Frank ${ }^{2}$ \\ Published online: 9 September 2020 \\ (C) Southern Criminal Justice Association 2020
}

Publisher Correction: American Journal of Criminal Justice https://doi.org/10.1007/s12103-020-09561-1

Due to typesetting mistake, the last two rows of Table 6 were misaligned. The original version has been corrected.

The online version of the original article can be found at https://doi.org/10.1007/s12103-020-09561-1

Omeed S. Ilchi

oilchi@westfield.ma.edu

1 Department of Criminal Justice, Westfield State University, Westfield, MA, USA

2 School of Criminal Justice, University of Cincinnati, Cincinnati, OH, USA 